\title{
Reply to: Letter to the editor regarding "Long-term intubation and high rate of tracheostomy in COVID-19 patients might determine an unprecedented increase of airway stenoses: a call to action from the European Laryngological Society" by Piazza et al
}

\author{
Cesare Piazza ${ }^{1,2} \cdot$ Marta Filauro $^{3,4}\left([) \cdot\right.$ Giorgio Peretti ${ }^{3,5}$
}

Received: 21 February 2021 / Accepted: 22 February 2021 / Published online: 1 March 2021

(c) The Author(s), under exclusive licence to Springer-Verlag GmbH, DE part of Springer Nature 2021

\section{Dear Editor,}

We read the Letter by Fiacchini et al. and strongly appreciated the authors' effort to hypothesize new pathological mechanisms which are responsible for the high rates of laryngotracheal junction injuries observed in patients affected by COVID-19 and submitted to prolonged intubation for management of related pneumonia. Although there are data available in the literature concerning COVID-19-associated coagulopathy, to date no documented cause-effect relationships with laryngotracheal mucosa and framework damage have been reported. Notwithstanding, this issue and the possible role of intraepithelial high viral load in the airway merit prospective studies in this population at high-risk for developing laryngo-tracheal stenosis (LTS). However, as reported in our paper [1], the main etiopathogenetic mechanism responsible for the increased incidence of LTS in COVID-19 patients managed in the intensive care unit seems to be prolonged endotracheal intubation (possibly causing mucosal ulceration, granulomas, and webs),

This reply refers to the comment available online at https://doi. org/10.1007/s00405-021-06664-1.

Marta Filauro

mfilauro@yahoo.com

1 Unit of Otorhinolaryngology-Head and Neck Surgery, ASST-Spedali Civili of Brescia, Brescia, Italy

2 Department of Medical, Surgical and Radiological Sciences and Public Health, University of Brescia, Brescia, Italy

3 Unit of Otorhinolaryngology-Head and Neck Surgery, IRCCS Policlinico San Martino, Genoa, Italy

4 Department of Experimental Medicine (DIMES), University of Genoa, Genoa, Italy

5 Department of Surgical Sciences and Integrated Diagnostics (DISC), University of Genoa, Genoa, Italy with the subsequent addition of further damage from tracheostomy (determining tracheal rings fracture, collapse, necrosis, malacia, and superinfection). To try to avoid these kinds of airway injuries, it is of paramount importance to prevent the use of large-caliber tubes and to keep safe cuff pressure values between 20 and $30 \mathrm{~cm} \mathrm{H}_{2} \mathrm{O}$, as generally recommended in every pre-COVID-19 anesthesiologic and intensivist good practice guidelines. In fact, although such attention is routinely made in daily clinical practice, during the pandemic the primary health emergency and shortage of experienced personnel may have determined misconduct in the management of such complicated clinical scenarios, with use of tubes larger than normal, whose cuff had been inflated with high pressure, all maintained in place for an undue long period of time. Even now, an international consensus concerning the correct timing of tracheostomy is lacking, while high heterogeneity in national guidelines and protocols persists. In fact, European guidelines [2, 3] push for a more aggressive approach with an early tracheostomy, as opposed to North American [4], Canadian [5], and others advocating more conservative management, with delayed tracheostomy waiting for at least 14 days after orotracheal intubation or a negative COVID-19 test. The obvious (but undemonstrated) benefit of such a wait-and-see policy would be to reduce the risk of contamination of healthcare workers: an argument preventable by the adequate use of personal protective equipment, if not by the recently accomplished vaccination program. Moreover, none of the above-mentioned guidelines discusses the advantages of performing early tracheostomy in COVID-19 patients: in fact, if it does not offer a dramatic benefit in ventilator weaning, it would undoubtedly reduce the complications from prolonged intubation.

In conclusion, underlying the fact that prolonged intubation (with delayed tracheostomy) represents the leading cause of the increased incidence of LTS in COVID-19 
patients, we reinforce our recommendations to follow good practice guidelines in place before the pandemic: in no way should such rules in use during the pre-COVID-19 era be changed in the days to come.

Funding No support was received for the preparation of the manuscript.

\section{Declarations}

Conflict of interest The authors declare that they have no conflict of interest.

\section{References}

1. Piazza C, Filauro M, Dikkers FG et al (2021) Long-term intubation and high rate of tracheostomy in COVID-19 patients might determine an unprecedented increase of airway stenoses: a call to action from the European Laryngological Society. Eur Arch Otorhinolaryngol. https://doi.org/10.1007/s00405-020-06112-6
2. de Cerio D, Canduela P, Ferrandis Perepérez E, Parente Arias $P$ et al (2020) Recomendaciones de la Sociedad Española de Otorrinolaringología y Cirugía de Cabeza y Cuello para la realización de traqueotomías en relación con pacientes infectados por coronavirus COVID-19. Acta Otorrinolaringol Espan. https://doi. org/10.1016/j.otorri.2020.03.001

3. Schultz P, Morvan JB, Fakhry N et al (2020) French consensus regarding precautions during tracheostomy and post-tracheostomy care in the context of COVID-19 pandemic. Eur Ann Otorhinolaryngol Head Neck Dis. https://doi.org/10.1016/j.anorl .2020.04.006

4. Miles BA, Schiff B, Ganly I et al (2020) Tracheostomy during SARS-CoV-2 pandemic: recommendations from the New York Head and Neck Society. Head Neck 42:1282-1290. https://doi. org/10.1002/hed.26166

5. Sommer DD, Engels PT, Weitzel EK et al (2020) Recommendations from the CSO-HNS taskforce on performance of tracheotomy during the COVID-19 pandemic. J Otolaryngol Head Neck Surg 49:23. https://doi.org/10.1186/s40463-020-00414-9

Publisher's Note Springer Nature remains neutral with regard to jurisdictional claims in published maps and institutional affiliations. 